\title{
Integration Processes in Education: Classification of Integration Types
}

\author{
Albina R. Shaidullina ${ }^{1}$, Nailya A. Pavlova ${ }^{2}$, Venera N. Minsabirova ${ }^{3}$, Elena A. Burdukovskaya ${ }^{4}$, Aislu B. \\ Yunusova $^{5}$, Valeryi A. Letyaev ${ }^{3} \&$ Anton S. Afanasev $^{3}$ \\ ${ }^{1}$ Almetyevsk State Oil Institute, Almetyevsk, Russia \\ ${ }^{2}$ Naberezhnye Chelny Institute of Social-Pedagogical Technologies and Resources, Naberezhnye Chelny, \\ Russia \\ ${ }^{3}$ Kazan (Volga region) Federal University, Kazan, Russia \\ ${ }^{4}$ Amur State University, Blagoveschensk, Russia \\ ${ }^{5}$ R. G. Kuzeev Institute for Ethnological Studies, Ufa Scientific Center of the Russian Academy of Sciences, Ufa, \\ Russia \\ Correspondence: Albina R. Shaidullina, Foreign Languages' Department, Almetyevsk State Oil Institute, \\ Almetyevsk, 423450, Russia. E-mail: albina-plus@mail.ru
}

Received: December 29, 2014 Accepted: January 22, 2015 Online Published: February 27, 2015

doi:10.5539/res.v7n4p27

URL: http://dx.doi.org/10.5539/res.v7n4p27

\begin{abstract}
The relevance of the stated problem is due to the fact that integration is a system formation that combines procedural and resulting components contributing to the appearance of a system's new integrative quality, which cannot be reduced to the sum of the qualities of its autonomous elements. The paper presents a theoretical justification for the classification of types of integration: by quality characteristics of an integrated system (unproductive integration, quasi-integration, preproductive integration, productive integration); by presence of necessary components of an integrated system (full integration, partial integration, disintegration); by temporal characteristics of an integrated system (episodic integration, periodic integration, systematic integration); by types of integrating subjects (sectoral integration, inter-sectoral integration, allied integration). The article submissions represent a theoretical value to researchers concerned with integration issues, and also have practical significance for subjects of the integrated system of "education-production" in order to prepare specialists meeting the requirements of modern production.
\end{abstract}

Keywords: integration processes, classification, types of integration, integrated system, education, production

\section{Introduction}

When studying the problem of integration we should proceed from the position that the integrity of an integrated system is ensured by consistency of its interacting elements, which are characterized by internal and external connections, where their deepening and broadening are carried out due to the compliance with the law of harmonic balance (Cheshev, 2012; Filippov, 2003; Shaidullina \& Ziyatdinov, 2013; Nikiforov \& Fayzullina, 2007). The imperative of self-transformation is provided by structural heterogeneity, which gives rise to contradictions and new growing points in the system, because it is exactly in a non-structured situation when the protective mechanisms of adaptation are triggered in the system (Hodgson, 2011; Kozminski, 2003; Petrov, 2009; Smirnov \& Tkachenko, 2004).

Understanding the system as an integrated set of interrelations and interdependencies takes place through interchanging with the environment, and therefore, it seems relevant to consider different implementations and manifestations of these relations. Currently, there are different strategies for integrating both educational and industrial structures. One of the most common classifications divides integration into vertical and horizontal. Practice shows that if a vertically integrated company is composed of at least one unit having a weak position, then the entire structure turns out to be strategically nonviable, or if an adjacent sector being integrated has a high level of competition, the company may worsen their position in the market, limiting work by attachment to one supplier or one consumer instead of making market transactions.

\section{Methodological Framework}

As a methodological basis of the study of this problem there were the following general scientific principles: 
1) The principle of synergetics, suggesting an increase in the number of coherent linkages to facilitate emergence of qualitatively new features of an integrated system. This principle not only justifies integration of educational institutions in the required time to obtain a certain result, but also offers the prospect for motion, formation, as the evolutionary process has two poles: chaos and order. Complexity of the structure of integration relations in the process of this evolution implies emergence of alternative patterns of the future, where the future of this system is characterized by a coherent structure (Ursul, 2008).

2) The principle of symbiosis aimed at strengthening the relationship between the elements of an integrated system in order to create the system integrity. Self-regulation of the new system, its self-development depend on the operation of each element, which is seen as a link in an integrated system and aimed at addressing different parts of a general problem of the system. Each element of the integrative system can maintain a certain degree of its freedom, but at the same time should be aimed at stimulating the activity of a holistic integrated system (Ibragimov, 2011; Mukhametzyanova, 2005; Masalimova \& Shaidullina, 2006).

3) The principle of relevance, allowing the formation and development of integrated forms of interaction by combining previously disparate parts and components into a single unit. A necessary condition for transition of the self-organizing system to a new level is not only a reorganization of its internal structure, but also the process of filling in its subsystems based on the interaction with the external environment. Consequently, the process of filling takes place only as a result of the initial structural heterogeneity, which incites the elements to self-filling and acquiring a single integrity (Shaidullina \& Fatkhullina, 2013; Mukhametzyanova \& Shaidullina, 2011).

4) The principle of clustering, implying integration of professional schools of different levels according to different sectors. An important feature of an integrated system is that it works much better in terms of an educational cluster in which the actions of its subjects lead to more consistent, objective and mutually beneficial relations, which are of mediated consolidation of subjects' interests of the system, involving collegiality in decision-making and corporative responsibility (Tkachenko, 2001; Novikov, 2005; Merzon et al, 2015).

5) The principle of systemacity, implying smooth mutual convergence and complementarity of both external and internal elements of an integrated system. This principle not only updates the integration of educational institutions into a single system, related in preparation of competitive and sought-after experts, but also indicates the preferred direction for the development of the educational system - namely, its integration and harmonization of standards, connecting the outputs of some educational institutions (of lower order, for example, secondary schools) with others (of higher order, such as colleges and universities) Mrathuzina, et al, 2015).

\section{Results}

Consideration of the set of integrated relations in educational and industrial structures allowed highlighting also other classifications of integration types in the study:

1) By the presence of the necessary components in the integrated system:

- Full integration, which implies not so much maximality of the relations of subjects in the integrated system and of their components (integration of educational institution types, of the levels, of professional training content, of organizational and administrative processes, etc.) as a full cycle of necessary relations being implemented to achieve the integrity of the integration processes;

- Partial integration, implying interaction of individual elements or levels of an integrated system;

- Disintegration, characterized by lack of integration;

2) By qualitative characteristics of an integrated system:

- Unproductive integration, implying the interaction of subjects of an integrated system only at a formal level with a predominance of monologue forms of cooperation, characterized by lack of relations between education and the labor market;

- Quasi-integration, which implies an oversimplification of integrated system relations by following abstract patterns and not completely justified principles;

- Preproductive integration, implying the interaction of an integrated system's subjects with the dominant role of the labor market being dominated by monologue forms of cooperation, partly alternated by a dialogue between the system of professional education and employers - the subjects of the labor market;

- Productive integration, which implies equal cooperation of an integrated system's subjects, based on dialogic forms of cooperation which will balance supply and demand;

3) By temporal characteristics of an integrated system: 
- Episodic integration, implying temporary, fragmentary interaction between subjects of an integrated system according to their simultaneous requirements;

- Periodic integration, characterized by a long-term relationship of an integrated system's subjects, dependent on the social order of the society at certain times and assumed to be discrete by nature;

- Systematic integration, assumed to have continuous and permanent relations of an integrated system's subjects for sustainable development and self-development of the system;

4) By the type of a system's integrating subjects:

- Sectoral integration, implying interaction of subjects within one department;

- Cross-sectoral integration, implying interaction of subjects in different types of departments which may be included in one and the same cluster;

- Allied integration (intercluster), implying interaction of subjects of the same or different types of departments between different clusters.

Identification of the above types of education and production integration is due, on the one hand, to the insufficiency of quantitative indicators alone for their productivity and on the other - not all relations must be systematic and continuous by nature.

Integration is a pervasive process of moving of internal and external relations, occurring in the environment due to the law of harmonic balance, which can be achieved only in an unstable result. Therefore, only a process can be stable, but not the result and the system must always be structurally inhomogeneous and hence unstable (Masalimova et al., 2014; Shaidullina, 2012). The starting point of any evolution is a contradiction, which encourages elements to give rise to a new order. Only systems far from equilibrium, in a state of instability, can spontaneously organize themselves and develop.

\section{Discussions}

Revealing the essentially-categorical characteristics of integration, V. A. Engelhardt distinguishes three stages of partial and full integration: a) emergence of relations between the parts; b) loss by the parts of their initial identification qualities when entering into the composition of the whole; c) appearance of new characteristics in the emerging integrity, caused both by the properties of the parts and the emergence of new relations between the parts (Engelhardt, 1970).

A content analysis of the relationship of integration, disintegration, differentiation and dedifferentiation is represented in the works of a German author Paveltsig $(1989,1966)$. Multidimensional vision of integration, exhibited by the German researcher, contributes to an adequate understanding of the role of integration and disintegration processes in the implementation of educational activities. The realization, that any integration contains a disintegration moment, warns teachers from the "gross" approach to integration as "absolute good" and to differentiation-as "absolute evil" (M. K. Petrov). Significant contribution to the understanding of the integration essence is the arguments made by G. Paveltsig on the relationship in integration, assimilation and dissimilation; on the integration aspect of adaptation; on fusion unity and various phases of integration; on the interaction of "integration" and "process", "integration" and "development", "integration" and "progress" concepts. Extremely important for pedagogy is G. Paveltsig's position that we cannot let disintegration of the old not come to the fore, "while integration of the new system is still being put on the agenda" (Paveltsig, 1989).

The literature also addresses the genetic aspects of integration, proposes approaches to the allocation of objective reasons, conditions and factors of knowledge integration (Gott et al., 1984); describes the structural and morphological characteristics of it-levels, types, kinds, forms, directions, trends and mechanisms (Asimov \& Tursunov, 1981; Kedrov, 1984; Belyayeva et al., 1987; Kedrov, 1985).

Nature of the relationship of social and natural sciences is disclosed in Y. A.Schrader's work, in which the emphasis is not on the cooperation of independent partners, but on the mutual "intergrowth" or "close symbiosis of organisms" (Schrayder, 1990). G. D. Gachev raises the issue of the influence of the humanities on the development of natural science. The central point here is the ability of the humanities "to give an image of the Whole" (Gachev, 1991).

Careful attention is required to the works, which disclose an objective basis of the relationship of technical and social sciences. The researchers emphasize, that since the beginning of technical activities, equipment could not have been created without "having been humanized" beforehand, which subsequently affected the development of its conceptual apparatus that includes a number of concepts that have "anthropomorphic" character; the idea of interdependent nature of human existence and technology is formulated (Ukraintsev, 1973). N. K. Chapaev identifies ways of interaction of social and engineering sciences (Chapaev \& Weinstein, 2007); V.M. Kedrov writes about the principles underlying 
the relationship between sciences in general, as well as public and technical ones in particular (Kedrov, 1985). Typology and mechanisms of the relationship of technical and social sciences are discussed 9Branch of the Institute of History of Science and Technology, Academy of Sciences of the USSR (1972).

\section{Conclusion}

The main means of enhancing integration processes can only be their respective organization, since the imperative of self-organization is in the emergence of new growing points in the structure of the system, reinforcing its structural heterogeneity and instability, and therefore leading to the emergence of a new order, where the condition, enhancing the efficiency of these processes, will be a developed subjectivity of the system, i.e. the ability to organize itself. The system is considered to be self-organizing if without any external intervention it acquires a functional structure that allows it to evolve through the implementation of a full cycle of self-fulfillment. This explains the fact that most clearly the integration processes were manifested in regions distant from major scientific and educational centers of the country, and without having considerable scientific potential, as during critical periods of the country the integration became the main means of survival and self-preservation for provincial universities and research organizations, where integrative relations allowed them to evolve not at the expense of each other, but for the benefit of each other.

Consideration of the set of integrated relations of educational and industrial structures allowed us to identify the following classifications of integration types: by quality characteristics of an integrated system (unproductive integration, quasi-integration, preproductive integration, productive integration); by the presence of the necessary components of an integrated system (full integration, partial integration, disintegration); by temporal characteristics of an integrated system (episodic integration, periodic integration, systematic integration); by types of integrating subjects (sectoral integration, inter-sectoral integration, allied integration).

\section{References}

Asimov M., \& Tursunov A. (1981). Current trends integration of social, natural and technical sciences. Problems of Philosophy, 3, 57-69.

Belyayeva, A. P., Misheva P., \& Kodytek, A. (1987). Methodological problems of research and Professional and technical education (p. 199). Moscow: Higher School.

Branch of the Institute of History of Science and Technology, Academy of Sciences of the USSR. (1972). The relationship of technical and social sciences (p. 322). Leningrad: Materials Conf.

Carlgren, F. (1991). Anthroposophic way of knowing (p. 159). Moscow: RTC.

Chapaev, N. K., \& Weinstein, M. L. (2007). The integration of education and production: methodology, theory, experience: A monograph (p. 408). Ekaterinburg: IRRO.

Cheshev, V. V. (2012). Behavioral and activity adaptation: General and special. TSPU, 4, 230-234.

Engelgart, V. A. (1970). Integratism-A way from simple to the complex in the knowledge of the phenomena of life. Problems of Philosophy, 11, 103-115.

Filippov, V. M. (2003). The task of modernization of education at the present stage. Higher education today, 3, 25

Gachev, G. D. (1991). Book of surprise or science through the eyes of a humanitarian or images in science (p. 272). Moscow: Pedagogy.

Gott, V. S., Semeniuk, E. P., \& Ursula, A. D. (1984). Categories of modern science (p. 269). Moscow: Thought.

Hodgson, J. (2011). Socio-economic impacts of progress of knowledge and the growth of complexity. Problems of Economics, 8, 31-45.

Ibragimov, G. I. (2011). Innovative learning technologies in the conditions of implementation of competence-based approach. Innovations in Education, 4, 4-15.

Kedrov, B. M., Ogurtsov, P. V., \& Smirnov, P. V. (1984). Interaction of Science: Theoretical and Practical Aspects (p. 320). Moscow: Nauka.

Kedrov, V. M. (1985). Classification of Sciences: The Marx's science of the future (p. 543). Moscow: Thought.

Kozminski, A. (2003). The role of higher education in the reform of society in the context of globalization: Academic reliability and the desire to improve the level of universities. Higher education today, 3, 34-38.

Masalimova, A. R., \& Shaidullina, A. R. (2006). Foreign experience of integration of research, teaching and practice of students of higher technical school. Kazan Pedagogical Journal, 5(47), 54-61. 
Masalimova, A. R., Zakirova, V. G., Chernova, Y. A., Drovnikov, A. S., Shaidullina, A. R., \& Sakhieva, R.G. (2014). Structure and content of mentors psychological and pedagogical training curriculum. Life Science Journal, 11(7s), 381-386.

Merzon, E. E., Fayzullina, A. R., Ibatullin, R. R., Krylov, D. A., Schepkina, N. K., \& Pavlushkina, T.V. (2015). Organizational and pedagogical conditions of academic mobility development of students at school of higher professional education. Review of European Studies, 7(1), 46-51.

Mrathuzina, G. F., Fayzullina, A. R., \& Saglam, F. A. (2015). Substantive, Methodological and Organizational Discourse in Oriental History Learning at School and University. Review of European Studies, 7(1), $57-62$.

Mukhametzyanova, G. V. (2005). Professional education: Problems of quality and academic support (p. 319). Magarif Press.

Mukhametzyanova, G. V., \& Shaidullina, A. R. (2011). Regional Integration Processes in the Vocational Education System (1st ed., p. 232). Idel Press.

Nikiforov, Y. N., \& Fayzullina, A. R. (2007). Migration processes in the Republic of Bashkortostan. Bulletin of the University of Perm. Politics Series, 1, 240-244.

Novikov, A. M. (2005). Development of national education: Polemical reflections (p. 176). Egves Press.

Paveltsig G. (1966). Integration Ais Philosophische. Deutsche Zeitschrift fur philosophie, 9, 23-24.

Paveltsig G. (1989). Integrative trends in the modern world and social progress (pp. 27-42). Moscow: Publishing House of the Moscow University.

Petrov, M. K. (2009). System approach to the organization of a regional research center (p. 223). Rostov-na-Donu.

Schrayder, Y.A. (1990). The unity of the interaction of social and natural sciences (p. 108). Moscow: Nauka.

Shaidullina, A. R. (2012). Regional Experience of Integration in System Vocational School-High School-Manufacture. Memoirs of Almetyevsk State Oil Institute, 2, 306-312.

Shaidullina, A. R., \& Fatkhullina, R. A. (2013). Education system of innovative entrepreneurship in continuing professional education. Theory and practice of modern vocational education, 1, 134-138.

Shaidullina, A. R., \& Ziyatdinov, A. M. (2013). Electronic Science and Technology Journal as a mechanism for the integration of science, education and industry. Herald of Kazan Technological University, 16, 78-81.

Smirnov, I. P., \& Tkachenko, E. V. (2004). Social partnership: What awaits employers? (Results of the pilot the All-Russian social studies) (p. 32). Aspect Press.

Tkachenko, E. V. (2001). Basics regionalization basic vocational education (p. 42). Centre APO Press.

Ukraintsev, B. S. (1973). Link natural and social sciences in technical knowledge (pp. 74-95). Moscow: Nauka.

Ursul, A. (2008). Principle of temporal integrity and education. Herald of high school, 3, 28-35.

\section{Copyrights}

Copyright for this article is retained by the author(s), with first publication rights granted to the journal. This is an open-access article distributed under the terms and conditions of the Creative Commons Attribution license (http://creativecommons.org/licenses/by/3.0/). 